\title{
From the Five Aggregates to Phenomenal Consciousness
}

\author{
Towards a Cross-Cultural Cognitive Science
}

JAKE H. DAVIS AND EVAN THOMPSON

\begin{abstract}
Introduction
Buddhism originated and developed in an Indian cultural context that featured many first-person practices for producing and exploring states of consciousness through the systematic training of attention. In contrast, the dominant methods of investigating the mind in Western cognitive science have emphasized third-person observation of the brain and behavior. In this chapter, we explore how these two different projects might prove mutually beneficial. We lay the groundwork for a cross-cultural cognitive science by using one traditional Buddhist model of the mind - that of the five aggregates - as a lens for examining contemporary cognitive science conceptions of consciousness.

The model of consciousness and meditative transformations of consciousness that we offer in this chapter is inspired by the accounts found in the Pāli Nikāyas. For this reason and for the sake of simplicity, we make reference especially to Pāli textual sources and terminology. Nevertheless, it is important to note at the outset that these texts admit of multiple possible readings. Our reconstruction differs in certain respects from the traditional interpretation of the five aggregates in the Theravāda Buddhist commentaries on the Pāli Nikāyas. Our aim, however, is not to give an historical account of what these concepts meant at any point in the development of Buddhist thought; and we make no claim that anyone in the Buddhist tradition, early or late, actually understood this model in the way we suggest. The model of attention, consciousness, and mindfulness that we draw from the Nikāya account of the five aggregates is of interest to us because it suggests promising new directions for scientific investigations of the mind. Put another way, whatever value our model has lies not in any claim to historical authenticity but, rather, in its claim to being empirically accurate and productive of further research.

Situating Buddhist views within recent scientific debates about consciousness allows us to see how these views might be tested experimentally and thereby opens up new
\end{abstract}

A Companion to Buddhist Philosophy, First Edition. Edited by Steven M. Emmanuel.

(C) 2014 John Wiley \& Sons, Inc. Published 2014 by John Wiley \& Sons, Inc. 
understandings of what these ancient teachings mean for us today. At the same time, understanding the conceptual frameworks of the Buddhist teachings can help scientists to refine the theoretical frameworks they bring to research on meditation and consciousness. This opportunity is lost if we simply apply existing scientific frameworks to interpret data from experiments on Buddhist meditation practices.

The burgeoning scientific literature on "mindfulness" meditation offers a case in point. This form of meditation can be broadly characterized by the aim to cultivate a lucid awareness of one's own moment-to-moment bodily, emotional, perceptual, and cognitive processes. Seeing the potential for this technique in medical settings, Jon Kabat-Zinn pioneered in the 1980s the Mindfulness-Based Stress Reduction program (MBSR). MBSR is now offered in the secular context of hospitals and clinics around the world and has become the subject of a burgeoning scientific literature. Kabat-Zinn's approach was influenced by Korean Zen Buddhist teachings as well as by Advaita Vedanta, and the particular technique he incorporated into MBSR was directly inspired by Theravāda Buddhist teachers drawing on texts from the Pāli discourses such as the Mahāsatipațțhāna Sutta, or "Longer Discourse on Mindfulness" (DN.II.290-315). Yet, attempts in the scientific literature to formulate what mindfulness is have often proceeded in almost total independence from theoretical formulations of mindfulness practice contained in Buddhist textual traditions. In the absence of references to such traditional canonical sources, there has been an inordinate focus on one particular phrase Kabat-Zinn used in his seminal introductory guide for practitioners to describe mindfulness - namely, "paying attention in a particular way: on purpose, in the present moment, and nonjudgmentally" (Kabat-Zinn 2004, 4).

When specific references occur in the scientific literature to the Buddhist textual sources, these references often consist in noting that the term "mindfulness" is a translation of the Pāli term sati. In Buddhist theory, however, the term sati carries connotations of memory and remembrance, making attempts to understand mindfulness as a present-centered, non-elaborative, and non-judgmental attention appear inaccurate and confused (see Bodhi 2011; Dreyfus 2011). Indeed, the term "mindfulness" seems to have been chosen by early translators of the Pāli texts because they saw parallels not with a notion of non-judgmental present-centered attention but, rather, between the Christian ethical notion of conscience and the textual usage of sati in the context of holding in mind and being inspired by certain truths, for the sake of improvement of one's ethical character (Gethin 2011). The broad usage of the term sati is perhaps best captured by the colloquial English notion of "minding." The Pāli texts employ sati in reference to everything from "minding" one's livestock (MN.I.117) to "minding" one's meditation object in practices such as lovingkindness (Sn.26), in addition to using sati specifically in the context of mindfulness meditation or, more literally, in the establishment of sati (sati-upatthāna). ${ }^{1}$ In this general sense, sati clearly can involve elaborative and evaluative cognitive processes. In the role sati plays in the context of mindfulness meditation, however, the involvement of memory may be of a more limited and specific kind.

In order to investigate properly a given type of meditation practice, scientists must take account of the traditional theoretical frameworks used to conceptualize and teach that practice (Lutz et al. 2007). We outline here how the traditional theoretical context of mindfulness practice can offer important suggestions for scientific research. In par- 
ticular, the five aggregates model draws distinctions that are not always clearly formulated in contemporary cognitive science, but that are crucial for a scientific understanding of the function of mindfulness meditation. We suggest below how empirical hypotheses about the role of memory and its relation to attention and consciousness in mindfulness meditation can be refined in light of distinctions suggested in the Buddhist five aggregates model.

\section{A Buddhist Model of the Mind}

The Buddhist five aggregates model parallels a number of distinctions drawn in cognitive science and therefore serves as a useful theoretical resource for developing a cross-cultural cognitive science of consciousness (Varela et al. 1991). In the Pāli texts the five aggregates (khandhas) are listed as rūpa, vedanā, sañ̃nā, samikhāra, and viññāna. Deciding what each of these words means, however, is not straightforward. Indeed, as we will see, interpreting the khandhas raises philosophical issues that directly connect with contemporary debates about consciousness.

The first aggregate, rūpa, is often understood as referring simply to the physical matter of the body. In the Pāli dialogues, however, this term connotes not only the body's solidity and extension but also its mobility, temperature regulation, fluid, and digestive systems, as well as its processes of decay. For this reason, some textual scholars suggest that rūpa is better understood as referring to the "lived body rather than simply its flesh" (Hamilton 2000, 29). On this reading, the conceptual framework of the five khandhas anticipates contemporary cognitive scientific and phenomenological accounts of the bodily basis of cognition, emotion, and consciousness (see Thompson 2007 for an overview).

Bodily changes such as the contraction of the gut and the flush of blood in anger have long been recognized as central to emotion. William James (1884) proposed that emotions essentially are such bodily reactions, an idea that still plays an important role in emotion theory today; for example, the neuroscientist Antonio Damasio (2000) and the philosopher Jesse Prinz (2004) have both argued that emotions are constituted in part by bodily reactions. But emotion theorists also recognize a second aspect of emotion, one that takes us from rūpa construed as the living body to vedanā, the second of the five khandhas. This second aspect is the specific feeling tone belonging to a given emotion. Some emotions feel pleasant and others feel unpleasant. When we consciously feel joyful, the experience is pleasant, and when we feel fearful, the experience is unpleasant. Psychologists call this aspect of emotion its affective valence or hedonic tone (see Colombetti 2005 for the complicated history behind this concept of "valence").

The notion of affect valence provides a close analogue to the Buddhist notion of vedanā. In the Khajjaniya Sutta (SN.III.86-7), vedanā is defined as feeling pleasure, feeling pain, or feeling neither-pleasure-nor-pain. In the case of both concepts, valence and vedana $\bar{a}$, the feeling tone of pleasant versus unpleasant is closely related to action tendencies of approach versus avoidance. From the modern neuroscience perspective, the bodily responses constitutive of an emotion, including an emotion's valence and action tendency, can be activated even when we do not report consciously feeling the emotion 
(LeDoux 2000). For example, we may exhibit bodily responses associated with fear, even though we do not report seeing anything fearsome or feeling fearful. Thus, like vedanā, valence motivates us at implicit as well as explicit levels. Moreover, recent work has shown that such implicit affect valence is not limited to emotional episodes and influences decision-making on everything from consumer choices to moral judgment (Loewenstein and Lerner 2003). This understanding of the pervasive role of affect valence in human psychology finds a parallel in the Buddhist suggestion that vedanā is present with every mental state, not just those Western psychology includes under the emotions.

In understanding the function of meditative training in bringing about personal transformation, the habits of mind that dispose an individual to perceive and react to the world in certain distinctive ways are of obvious importance. These habits of mind fall under the fourth of the five aggregates, samkhära. This category can be understood as comprising all volitional activities. These include volitions that lead to outward action or what we normally think of as the will. But they also include more internal processes, such as attention, manasikāra - literally, "making-in-the-mind." Thus we can understand samkhāra as referring to implicit and habitual processing routines that shape how we perceive and behave and that typically escape explicit, cognitive awareness.

Importantly, these habits of mind not only shape our inner and outer actions but are themselves formed through the repetition of certain kinds of inner and outer volitional activities. Thus, in addition to conditioning the other four aggregates, the samkhāras involve dynamic self-reference and self-conditioning: habits are formed and conditioned by habits (SN.III.87). ${ }^{2}$ This conception parallels recent models of cognitive events as self-forming processes arising from non-linear interactions between components at neural and motor levels (Cosmelli et al. 2007). Complex (non-linear) dynamical systems have a feature known as sensitive dependence on initial conditions: a minute change in conditions at one point in time can greatly shift the trajectory of the system down the line. Similarly, the dynamic self-formation of the samkhäras allows for the possibility of radical transformation of one's personality traits. In the particular case of mindfulness meditation, the suggestion is that, by intentionally attending to present experience instead of dwelling in reactivity to the remembered past or the imagined future, we can radically transform the habits of attention that surface at moments of feeling threatened or tempted, and thereby transform the way we react outwardly to such situations.

Within this category of habits of mind, the role of attention is of particular interest for us here. In the Mahāhatthipadopama Sutta of the Majjhima Nikāya, for example, we find the following claim:

If the internal eye-organ is intact, but an external form does not come into its range ... If the internal eye-organ is intact, and an external form does come into its range, but there is not the bringing together born from that (tajja samannāhāra), there is not the appearance of a degree of consciousness born from that (tajja viññannabhāga). But when the internal eye-organ is intact, and an external form does come into its range, and there is the bringing together born from that, there is the appearance of a degree of consciousness born from that.

(MN.I.190) 
Despite other Pāli texts that omit the factor of "bringing together," samannāhāra, in the account of perceptual processes, this factor is clearly crucial in the above formulation: an external form coming into the range of an intact eye is said to result in a share or degree of consciousness only with the addition of this factor of bringing together. The traditional Pāli commentary glosses samannāhāra as here meaning manasikāra (attention). ${ }^{3}$ As the above formulation suggests, manasikāra is understood in this theoretical framework as a universal kind of attention necessary for any moment of consciousness. It may therefore correspond in a rough way to the basic kind of alertness required for the basal, core-level consciousness that Parvizi and Damasio (2001) hypothesize to be dependent on subcortical structures such as the thalamus and brainstem, and which occurs independently of the direction of this consciousness to particular objects through selective attention.

This core level of consciousness, which we discuss briefly below, stands in contrast to the more cognitive functions that allow one to identify, recall, and report what one experiences. These cognitive processes are the function of the third aggregate, sañña. In the Khajjaniya Sutta (SN.III.87), saññā is defined as cognizing (sañjānāti) that there is blue, that there is red, yellow, or white. The term sañña is often glossed as "perception," but this interpretation is inadequate. As the Pāli scholar Peter Harvey explains, sañña

is only one part of the perceptual process and ... one can have a sañña of a mental object but cannot, in English, be said to "perceive" such an object . . . the word "sañña" and its verbal form "sañ-jānāti" clearly refer to some kind of knowledge or knowing which is done in an associative, connective, linking (sa-) way.

(Harvey 1995, 141)

The Pāli texts contain some intriguing statements that suggest sañña may be akin to what the philosopher Ned Block $(2007,2008)$ calls "cognitive access," defined as the ability to recall, report, and deliberate on a perceptual event. The Nibbedhika Sutta (AN. III.413), for instance, defines sañ̃̃a as that which results in spoken communication (vohāra): "As one identifies (sañjānāti) it, so one says 'I saw thus."

Sañ̃ñ is differentiated in the Buddhist model of the mind from viññanna, the fifth aggregate, often glossed as "consciousness." It is tempting to relate this notion to what Block calls "phenomenal consciousness" (Block 2007, 2008). Whereas phenomenal consciousness consists in "what it is like" for a subject to have or to undergo an experience, cognitive access consists in having the content of an experience enter working memory so that one can identify and report on this content. Given this distinction, viññana, defined as a moment of visual, auditory, tactile, olfactory, gustatory, or mental awareness, would be analogous to phenomenal consciousness, whereas sañ̃ña, defined as a recognitional ability, would be analogous to cognitive access.

Yet this tentative analogy between Pāli Buddhist and cognitive science conceptions of consciousness needs refinement. Block conceives of phenomenal consciousness as a state of experiencing in a rich and vivid way certain objects or properties - for instance, a state of seeing red. Without such a notion of phenomenally conscious states as essentially including modality-specific content, it would make little sense to suggest, as Block does, that visual phenomenal consciousness might be realized by certain patterns of recurrent neural activity in visual areas of the brain (Block 2005). In contrast, Parvizi 
and Damasio (2001) suggest that there is a basic, core level of consciousness, dependent on the thalamus and brainstem, that occurs independently of selective attentional processes in higher cortical areas. This core or ground-floor level of consciousness depends on a basic kind of alerting function distinct from the higher-level mechanisms of selective attention that come into play in determining what one is conscious of. On this view, the fact that there is a phenomenal feel - the fact that there is something it is like for a subject - depends on the basic alerting function. In contrast, the content of phenomenal consciousness - what it is like for a subject - depends also on how this consciousness is directed to particular objects and properties through selective attention. Put another way, the particular contents of phenomenal consciousness can be seen as modifications or modulations of a basal level of awareness dependent on the alerting function (see also Searle 2000). We suggested above that the Pāli Buddhist concept of manasikāra may be analogous to this alerting function, rather than to selective attention. Correspondingly, viññāna may be best understood from this cognitive science perspective as analogous to a basal level of awareness common to all phenomenally conscious states.

We need to be cautious, however, in drawing any of the foregoing parallels between the third and fifth aggregates and cognitive science conceptions of cognitive access and consciousness. Currently there is no consensus in cognitive science about whether phenomenal consciousness and cognitive access are two different phenomena, or whether phenomenal consciousness depends constitutively on cognitive access. ${ }^{4}$ On the one hand, it seems odd to say that you can have a conscious experience that you do not know you are having. And if knowing that you are having a certain experience, such as a visual experience of the color red or a tactile experience of hardness, requires the cognitive functions of identifying the object or properties being experienced, then it seems problematic to postulate a type of experience that occurs independent of cognitive access. Furthermore, given that the principal scientific criterion for the presence of consciousness is behavioral report, and behavioral report requires cognitive access, how could such a subjective experience ever be investigated?

On the other hand, it seems unsatisfactory to assume, in advance of the evidence, that having a conscious experience consists wholly in various cognitive operations, such as identifying its content or identifying oneself as having experienced that content. Proponents of drawing a distinction between phenomenal consciousness and cognitive access need only posit that some instances of phenomenal consciousness happen not to be cognitively accessed; they need not posit that there are subjective experiences that the subject cannot access or know about. Indeed, one function of phenomenal consciousness may be to make its content accessible for encoding in working memory, for the purposes of identification, recall, deliberation, and report (Prinz 2005, 2011; see also Block 2011, 567). Certain experiences may be too fleeting and rapid to stabilize in working memory, as various kinds of evidence have sometimes been taken to suggest (see Block 2011; Kouider et al. 2010). Nevertheless, such experiences may not be inaccessible in principle; for instance, it may be possible to gain greater cognitive access to them through the kind of mental training central to mindfulness meditation.

We believe this last point indicates a major shortcoming in the current cognitive science discussions. These discussions have proceeded without significant consideration being given to the possibility that specific forms of mental training might be 
able to produce new data about attention and consciousness. Mental training and its relevance for understanding consciousness are areas where Buddhist theory and meditation practice have much to contribute, as we discuss in the next section.

\section{Varieties of Attention Training}

Many Buddhist traditions distinguish between meditation practices aimed primarily at concentrating the mind and meditation practices aimed primarily at developing wisdom. In a Buddhist context, concentration practices range from cultivating states such as lovingkindness or, literally, friendliness (mettā) to practices aimed simply at cultivating a settled and unified state of mind (samädhi) through concentration on a meditative object, such as the sensations of the breath or a visualized image of a colored disk or a light. In these forms of meditation, practitioners counteract mind-wandering by repeatedly bringing the mind back to the subject of meditation.

Concentration practices may have important contributions to make to our understanding of the processes responsible for stabilizing particular contents in consciousness. We can use studies of the perceptual phenomenon known as binocular rivalry to illustrate this point.

In normal vision, the brain receives visual images from each eye that present slightly differing views on the same scene. In the experimental paradigm known as binocular rivalry, however, each eye is presented with a different image at the same time. For example, one eye may receive the image of a house while the other eye receives the image of a face. Subjects generally report seeing one image at a time but also that their perception switches unpredictably between the two images. Thus, although the stimulus remains constant, visual consciousness changes as the two stimuli compete for perceptual dominance. On the one hand, the visual image that is not consciously seen provokes significant neural responses selective to its particular features. For example, the image of a fearful face has been found to activate the amygdala, an area of the brain associated with perceiving emotionally salient stimuli (Williams et al. 2004). On the other hand, voluntary shifts in attention have been shown to affect which image becomes consciously seen (Ooi and He 1999). For this reason, binocular rivalry paradigms have provided an important source of evidence for debates over consciousness and its relation to attention.

In an intriguing study of meditation and binocular rivalry, Olivia Carter and her colleagues found that long-term Tibetan Buddhist practitioners of concentration meditation were able to change the perceptual switching rate when they viewed the images while practicing this type of meditation (with eyes open focused on the display as the meditative object) (Carter et al. 2005). A large number of the practitioners reported that the amount of time one image remained perceptually dominant increased considerably while practicing concentration meditation as well as immediately after meditation. Three individuals reported that the image remained completely stable, with no switching, for an entire 5-minute period of concentration meditation. In some cases, one of the two images was completely dominant; in other cases, the non-dominant image remained faintly or partially visible behind the dominant one, so that the conscious perception was of two superimposed images. As Carter and her col- 
leagues observe, "These results contrast sharply with the reported observations of over 1000 meditation-naïve individuals tested previously" (ibid., 412). Thus, it may be that meditative training of voluntary attention enables long-term practitioners of concentration meditation to stabilize consciousness of one or the other image, or even to maintain conscious awareness of the non-dominant image, in a way that normal subjects are unable to do. If so, investigations of brain activity in meditators with expertise in concentration meditation may help shed light on the processes that make particular contents phenomenally conscious.

The use of various methods of attention training for developing altered states of consciousness through strong concentration was widespread at the time of the Buddha. Buddhist texts relate how, before his enlightenment, the Buddha studied techniques for concentrating the mind under teachers such as Ālāra Kālāma and Uddaka Rāmaputta (MN.I.237-51). Yet these early Buddhist texts also emphasize that the method of mind training that the Buddha went on to discover for himself was novel, with results that differ importantly from those that were being taught by his contemporaries. In a modern context, we can take this claim to be an empirical one, subject to experimental test, and hence one that may be best approached through a cross-cultural cognitive science based on both Buddhist and cognitive scientific models of attention and consciousness.

In addition to what cognitive scientists describe as the endogenous orienting network, which voluntarily allocates selective attention to a chosen object (Corbetta and Shulman 2002), concentration or "focused attention" styles of meditation involve a "monitoring" function necessary to detect when attention has wandered away from the chosen object (Lutz et al. 2008). Lutz and colleagues distinguish such "focused attention" practices from "open monitoring" practices, which may involve focused attention training at early stages of practice but use the development of the monitoring skill to be able eventually to drop any intentional selection or deselection within the field of present experience. Instead, meditators aim to remain attentive to whatever arises in momentto-moment experience, without becoming lost in mind-wandering. Open monitoring styles of meditation include certain Tibetan Buddhist and Chan/Zen practices, as well as Theravāda mindfulness practices.

Theravāda mindfulness meditation, or, more literally, the establishment of sati (satiupațthāna), involves returning the mind again and again to present-moment experience (for a discussion of this term, see Anālayo 2004, 29-30; Bodhi 2011). This practice thus includes an element of concentration, though different teachers emphasize the concentrative aspect to differing degrees. In other concentrative practices, one might return the attention again and again to a particular feeling of friendliness, or a particular mental image of color or light, thereby cultivating the continuity and stability of a particular object in the mind. In contrast, Theravāda mindfulness practice aims to develop a settled type of attention on objects that are constantly changing. Present experiences of heat or cool in the body, of anger or of joy, of concentration or of distractedness, constantly arise and pass away again. Theravāda Buddhist teachings claim that experiencing for oneself in this direct and lucid way the impermanent and unstable nature of all aspects of experience brings about a profound change in how one relates to oneself and others (e.g., Mahasi Sayadaw 1994). 
In our discussion of the five aggregates model above, we made a distinction between the particular sensory and mental contents of phenomenal consciousness and a basal level of consciousness dependent on an alerting function. Theravāda mindfulness meditation may hold particular promise for investigating this basal level of consciousness because this type of meditation is said to enhance the clear awareness of whatever arises but without using focused attentional selection. One way such enhanced phenomenal consciousness may be achieved is by a reduction in elaborative cognitive processes - the proliferation of evaluative thoughts about moment-to-moment stimuli - combined with increased alertness. Recent experimental studies of Theravāda mindfulness meditation are consistent with this idea.

Consider first a study of the effects of Theravāda mindfulness meditation on the so-called attentional blink. In this experimental paradigm, subjects have to identify two visual targets presented within 200 to 500 milliseconds of each other in a rapid sequence of other distracting visual stimuli. Subjects often notice the first target but fail to notice the second one, as if their attention had blinked. The standard explanation is that detecting the first target uses up the available attentional resources, so the second target is missed and not reported. A recent study showed that the ability to detect the second target was greatly improved after a three-month intensive Theravāda mindfulness meditation retreat, and that this improvement correlated with EEG measures showing more efficient neural responses to the first target (Slagter et al. 2007). Importantly, the participants were instructed not to meditate during the task, so the improved performance indicates that mindfulness meditation has lasting effects on attention outside of the context of meditation practice. The authors of this study suggest that mindfulness meditation may lead to less elaborative cognitive processing of the first visual target - less "mental stickiness" to it - and that this reduction facilitates the ability to identify and report the second rapidly occurring target.

The idea that enhanced phenomenal consciousness is linked to a reduction in elaborative cognitive processing as a result of mindfulness practice is also supported by recent work on mind-wandering and its association with the brain's so-called default mode network. The default mode network comprises a set of brain regions active in the resting state but whose activity decreases during externally directed and attention-demanding perceptual tasks (Buckner et al. 2008); these regions have also been shown to be active during mind-wandering (Mason et al. 2007; Christoff et al. 2009), including mindwandering during focused attention meditation conditions (Hasenkamp et al. 2012). Mindfulness meditation practice is associated with decreases in default mode network activation (Brewer et al. 2011; Berkovich-Ohana et al. 2012) and, importantly, with corresponding increased activation in visceral and somatic areas associated with interception (Farb et al. 2007, 2010).

According to traditional descriptions, mindfulness becomes effortless at advanced stages of practice. As the Burmese meditation master Mahasi Sayadaw (1994) puts it, "in the act of noticing, effort is no longer required to keep formations before the mind or to understand them." We noted above that, in the Pāli Buddhist framework, a basic and universal kind of attention, manasikāra, is held to be necessary for consciousness. The scholar-practitioner Anālayo suggests that sati "can be understood as a further development and temporal extension of this type of attention [manasikāra], thereby adding clarity and depth to the usually too short fraction of time occupied by bare 
attention in the perceptual process" (Anālayo 2004, 59). Whereas the focusing of attention in concentration practices involves activation of voluntary orienting networks, mindfulness practice may consist in enhancing the processes involved in sustaining alert consciousness more generally. If this were the case, then we should expect that long-term trait increases in one's consciousness of subtle stimuli (as opposed to transitory state increases) would be evident even in resting states.

\section{Conclusion}

To study the effects of therapeutic interventions on the brain and the rest of the body, scientists need to employ conceptual constructs of the phenomenon under investigation that guide where and how they look. Thus, in studying the health benefits and psycho-physiological processes underlying mindfulness meditation, scientists have had to ask what precisely mindfulness is (Davidson 2010). Yet attempts in the scientific literature to define mindfulness have often proceeded in almost total independence from theoretical formulations of mindfulness practice contained in Buddhist textual traditions. Fortunately, a new conversation between Buddhist textual scholars and cognitive scientists about the construct of mindfulness is gaining momentum (see the collection of articles in the June 2011 issue of Contemporary Buddhism).

Our goal in this chapter has been to provide some useful tools for this new conversation. In particular, building bridges between the five aggregates model and contemporary cognitive science can offer a way to understand more precisely the roles of attention, consciousness, and memory in Theravāda mindfulness meditation. Like other concentration practices, many forms of mindfulness meditation begin by employing working memory in directing selective attention - for instance, to the sensations of breathing. As we suggested above, however, the reduction of elaborative cognitive processing in mindfulness meditation may play a central role in advanced mindfulness practice, in particular by allowing for an increase in phenomenal consciousness of current stimuli. This mental transformation in turn has implications for what psychologists call "episodic memory" (the memory of particular experienced events), because increased phenomenal consciousness can facilitate accurate identification of what is experienced, as well as later recall and report. Drawing on the relation between the concepts of manasikāra and sati in the Pāli Nikāyas, we have further speculated that mindfulness meditation may function by enhancing the alerting function crucial for phenomenal consciousness.

As we noted at the outset of this chapter, however, these texts allow multiple interpretations, and the conception of manasikāra that we employ may not line up neatly with traditional interpretations in the Theravāda Buddhist commentaries. We suggest that the proposed relation between manasikāra and sati be treated as a testable hypothesis. Whatever value our model may have lies in its ability to suggest fruitful directions for future work in the cross-cultural cognitive science of consciousness.

We conceive of the discussion that we have undertaken here as one tentative step in a larger project of developing a cross-cultural cognitive science of Buddhist therapeutic interventions. One way to build on our discussion would be to develop a cognitive science perspective on the Buddhist claim that mindfulness counteracts not knowing, 
by increasing awareness of presently arising stimuli, and also counteracts knowing wrongly, by attenuating emotional distortions of attention, perception, and memory. Having taken that step from cognitive to emotional functions, a further project would be to examine critically, in the light of empirical work on attention, emotion, and moral psychology, the central Buddhist claim that certain emotional motivations are unskillful (akusala) and to be abandoned (pahātabbam); that other qualities are skillful (kusala) and to be cultivated (bhavitabbam); and that we can discern the difference for ourselves.

\section{Notes}

1 The term satipațțāna has commonly been rendered as a (plural) noun, the (four) "foundations of mindfulness." But the primary sense of the term is verbal and refers to the active practice of establishing mindfulness, as noted recently by prominent translators such as Bhikkhu Bodhi $(2011,25)$ and Thanissaro Bhikkhu (2011). For a critique of the more standard gloss of satipatțhanna as "foundations of mindfulness" and the commentarial derivation of the term from patțhāna on which this gloss is based, see Anālayo (2004, 29-30).

2 SN.III.87, "sańkhāre sañkhārattāya san̉khatam abhisañkharonti."

3 MN-a.II.229 (commentary to MN.I.190). In support of this interpretation, Harvey (1995, 129-30) notes that these terms are used as synonyms in the suttas, as at MN.I.445.

4 For a sampling of the debate, see Block (2005, 2011); Cohen and Dennett (2011); Kouider et al. (2010); and Lamme (2003).

\section{References}

Anālayo (2004). Satipațthāna: The Direct Path to Realization. Cambridge: Windhorse.

Berkovich-Ohana, Aviva, Glicksohn, Joseph, and Goldstein, Abraham (2012). MindfulnessInduced Changes in Gamma Band Activity - Implications for the Default Mode Network, Self-Reference and Attention. In Clinical Neurophysiology 123, 700-10. doi: 10.1016/j. clinph.2011.07.048.

Block, N. (2005). Two Neural Correlates of Consciousness. In Trends in Cognitive Sciences 9(2), 46-52. doi: 10.1016/j.tics.2004.12.006.

Block, N. (2007). Consciousness, Accessibility, and the Mesh between Psychology and Neuroscience. In Behavioral and Brain Sciences 30, 481-548. doi: 10.1017/S0140525X07002786.

Block, N. (2008). Consciousness and Cognitive Access. In Proceedings of the Aristotelian Society 108(3), 289-317. doi: 10.1111/j.1467-9264.2008.00247.x.

Block, N. (2011). Perceptual Consciousness Overflows Cognitive Access. In Trends in Cognitive Sciences 15, 567-75. doi: 10.1016/j.tics.2011.11.001.

Bodhi, Bhikkhu (2011). What Does Mindfulness Really Mean? A Canonical Perspective. In Contemporary Buddhism 12(1), 19-39. doi: 10.1080/14639947.2011.564813.

Brewer, Judson A., Worhunsky, Patrick D., Gray, Jeremy R., Tang, Yi-Yuan, Weber, Jochen, and Kober, Hedy (2011). Meditation Experience is Associated with Differences in Default Mode Network Activity and Connectivity. In Proceedings of the National Academy of Sciences 108, 20254-9. doi: 10.1073/pnas.1112029108. 
JAKE H. DAVIS AND EVAN THOMPSON

Buckner, Randy L., Andrews-Hanna, Jessica R., and Schacter, Daniel L. (2008). The Brain's Default Network. In Annals of the New York Academy of Sciences 1124(1), 1-38. doi: 10.1196/ annals.1440.011.

Carter, O. L., Presti, D. E., Callistemon, C., Ungerer, Y., Liu, G. B., and Pettigrew, J. D. (2005). Meditation Alters Perceptual Rivalry in Tibetan Buddhist Monks. In Current Biology 15, R412-R413.

Christoff, K., Gordon, A. M., Smallwood, J., Smith, R., and Schooler, J. W. (2009). Experience Sampling During fMRI Reveals Default Network and Executive System Contributions to Mind Wandering. In Proceedings of the National Academy of Sciences 106, 8719.

Cohen, Michael A., and Dennett, Daniel C. (2011). Consciousness Cannot Be Separated from Function. In Trends in Cognitive Sciences 15, 358-64. doi: 10.1016/j.tics.2011.06.008.

Colombetti, G. (2005). Appraising Valence. In Journal of Consciousness Studies 12(8-10), 103-26.

Corbetta, M., and Shulman, G. L. (2002). Control of Goal-Directed and Stimulus-Driven Attention in the Brain. In Nature Reviews Neuroscience 3, 201-15.

Cosmelli, D., Lachaux, J. P., and Thompson, E. (2007). Neurodynamical Approaches to Consciousness. In The Cambridge Handbook of Consciousness. Cambridge: Cambridge University Press.

Damasio, A. R. (2000). The Feeling of What Happens: Body and Emotion in the Making of Consciousness. London: Heinemann.

Davidson, R. J. (2010). Empirical Explorations of Mindfulness: Conceptual and Methodological Conundrums. In Emotion 10(1), 8-11.

Dreyfus, Georges (2011). Is Mindfulness Present-Centred and Non-Judgmental? A Discussion of the Cognitive Dimensions of Mindfulness. In Contemporary Buddhism 12(1), 41-54. doi: 10.1080/14639947.2011.564815.

Farb, N. A. S., Anderson, A. K., Mayberg, H., Bean, J., McKeon, D., and Segal, Z. V. (2010). Minding One's Emotions: Mindfulness Training Alters the Neural Expression of Sadness. Emotion 10(1), 25-33.

Farb, N. A. S., Segal, Z. V., Mayberg, H., Bean, J., McKeon, D., Fatima, Z., and Anderson, A. K. (2007). Attending to the Present: Mindfulness Meditation Reveals Distinct Neural Modes of Self-Reference. In Social Cognitive and Affective Neuroscience 2, 313.

Gethin, Rupert (2011). On Some Definitions of Mindfulness. In Contemporary Buddhism 12(1), 263-79. doi: 10.1080/14639947.2011.564843.

Hamilton, Sue (2000). Early Buddhism: A New Approach: The I of the Beholder. Richmond, Surrey: Curzon Press.

Harvey, Peter (1995). The Selfless Mind: Personality, Consciousness and Nirvana in Early Buddhism. London: Routledge.

Hasenkamp, Wendy, Wilson-Mendenhall, Christine D., Duncan, Erica, and Barsalou, Lawrence W. (2012). Mind Wandering and Attention during Focused Meditation: A Fine-Grained Temporal Analysis of Fluctuating Cognitive States. In NeuroImage 59, 750-60. doi: 10.1016/ j.neuroimage.2011.07.008.

James, William (1884). What Is an Emotion? In Mind 9, 188-205.

Kabat-Zinn, Jon (2004). Wherever You Go, There You Are. New York: Hyperion.

Kouider, Sid, Gardelle, Vincent de, Sackur, Jérôme, and Dupoux, Emmanuel (2010). How Rich Is Consciousness? The Partial Awareness Hypothesis. In Trends in Cognitive Sciences 14, 301-7. doi: 10.1016/j.tics.2010.04.006.

Lamme, Victor A. F. (2003). Why Visual Attention and Awareness Are Different. In Trends in Cognitive Sciences 7(1), 12-18. doi: 10.1016/S1364-6613(02)00013-X.

LeDoux, J. E. (2000). Emotion Circuits in the Brain. In Annual Review of Neuroscience 23, 155-84. 
Loewenstein, G., and Lerner, J. S. (2003). The Role of Affect in Decision Making. In Handbook of Affective Sciences. Ed. R. J. Davidson, K. R. Scherer, and H. H. Goldsmith. Oxford: Oxford University Press.

Lutz, Antoine, Dunne, John D., and Davidson, Richard J. (2007). Meditation and the Neuroscience of Consciousness. In The Cambridge Handbook of Consciousness. Ed. P. D Zelazo, Morris Moscovitch, and Evan Thompson. Cambridge: Cambridge University Press.

Lutz, Antoine, Slagter, Heleen A., Dunne, John D., and Davidson, Richard J. (2008). Attention Regulation and Monitoring in Meditation. In Trends in Cognitive Sciences 12, 163-9. doi: 10.1016/j.tics.2008.01.005.

Mahasi Sayadaw (1994). The Progress of Insight: (Visuddhiñana-katha). Trans. Nyanaponika Thera. At www.accesstoinsight.org/lib/authors/mahasi/progress.html\#ch6.11.

Mason, M. F., Norton, M. I., Van Horn, J. D., Wegner, D. M., Grafton, S. T., and Macrae, C. N. (2007). Wandering Minds: The Default Network and Stimulus-Independent Thought. In Science 315, 393-5. doi: 10.1126/science.1131295.

Ooi, T. L., and He, Z. J. (1999). Binocular Rivalry and Visual Awareness: The Role of Attention. In Perception 28, 551-74.

Parvizi, J., and Damasio, A. (2001). Consciousness and the Brainstem. In Cognition 79, 135-60.

Prinz, Jesse J. (2004). Gut Reactions: A Perceptual Theory of Emotion. New York: Oxford University Press.

Prinz, Jesse J. (2005). A Neurofunctional Theory of Consciousness. In Cognition and the Brain: The Philosophy and Neuroscience Movement. Cambridge: Cambridge University Press, 381-96.

Prinz, Jesse J. (2011). Is Attention Necessary and Sufficient for Consciousness? In Attention: Philosophical and Psychological Essays. Oxford: Oxford University Press, 174.

Searle, John R. (2000). Consciousness. In Annual Review of Neuroscience 23, 557-78. doi: 10.1146/annurev.neuro.23.1.557.

Slagter, Heleen A, Lutz, Antoine, Greischar, Lawrence L., Francis, Andrew D., Nieuwenhuis, Sander, Davis, James M., and Davidson, Richard J. (2007). Mental Training Affects Distribution of Limited Brain Resources. In PLOS Biology 5(6), e138. doi: 10.1371/journal.pbio.0050138.

Thanissaro Bhikkhu (2011). Translator's introduction to Maha-satipatthana Sutta: The Great Frames of Reference. Access to Insight. Retrieved December 16, 2011, from http://www. accesstoinsight.org/tipitaka/dn/dn.22.0.than.html

Thompson, E. (2007). Mind in Life: Biology, Phenomenology, and the Sciences of Mind. Cambridge, MA: Belknap Press.

Varela, E. J., Thompson, E., and Rosch, E. (1991). The Embodied Mind: Cognitive Science and Human Experience. Cambridge, MA: MIT Press.

Williams, Mark A., Morris, Adam P., McGlone, Francis, Abbott, David F., and Mattingley, Jason B. (2004). Amygdala Responses to Fearful and Happy Facial Expressions under Conditions of Binocular Suppression. In Journal of Neuroscience 24, 2898-904. doi: 10.1523/ JNEUROSCI.4977-03.2004. 
